\title{
Infâncias beiradeiras: crianças desordeiras
}

\author{
Edilma de Souza ${ }^{1}$ \\ https://orcid.org/0000-0002-7802-8201 \\ Maritza Maciel Castrillon Maldonado ${ }^{2}$ \\ https://orcid.org/0000-0001-6574-4463
}

\section{Resumo}

Encontrar em meio à floresta amazônica a alteridade da infância, é nesse movimento que este artigo se situa enquanto resultado de uma pesquisa desenvolvida no Mestrado em Educação. A infância que nos acolheu é composta por crianças ribeirinhas-amazônidas, que vivem às margens de um rio produzindo experiências infantis singulares e afirmativas da vida e frequentam uma Instituição de Educação Infantil. Essa infância é concebida neste texto enquanto potência criativa e agenciamentos coletivos de enunciação. Inspiramo-nos no método cartográfico desenvolvido pelos filósofos Deleuze e Guattari para produzir mapas rizomáticos que nos levaram às narrativas infantis ribeirinhas. As narrativas infantis são as potências deste texto na medida em que rompem com paradigmas que a história moderna nos acostumou em relação aos lugares reservados às crianças e às infâncias. Nossas inquietações se traduzem na seguinte questão: Como as crianças reverberam e criam táticas de resistências diante de tantos discursos que se enunciam sobre elas? Encontramos nas narrativas infantis os agenciamentos, os desvios e os acontecimentos-experiências que ecoam o quanto as crianças e as infâncias são novidades diante da soberba de nossa vontade de saber e poder.

Palavras-chave: Agenciamentos. Crianças ribeirinhas-amazônidas. Infâncias. Narrativas.

\begin{abstract}
Find in the middle of the Amazon forest the otherness of childhood, it is in this movement that this article stands as a result of a research developed in the Masters in Education. The childhood that welcomed us is composed of riverside-Amazonian children who live on the banks of a river producing singular and affirmative life experiences of children and attend an Institution of Early Childhood Education. This childhood is conceived in this text as creative power and collective assemblages of enunciation. We draw inspiration from the cartographic method developed by the philosophers Deleuze and Guattari to produce rhizomatic maps that have led us to children's riverside narratives. Children's narratives are the potencies of this text insofar as they break with paradigms that modern history has accustomed us to places reserved for children and childhoods. Our concerns are translated into the following question: How do children reverberate and create resistance tactics in the face of so many discourses that are stated about them? We find in child narratives the assemblages, deviations and events-experiences that echo how much children and childhoods are novelties in the face of the pride of our will to know and to be power.
\end{abstract}

Keywords: Assemblages. Riverside-Amazonian children. Childhood. Narratives.

\footnotetext{
${ }^{1}$ Estudante de Doutorado em Educação na Universidade Federal de Mato Grosso, Brasil. E-mail: edilmasz84@ gmail.com

${ }_{2}^{2}$ Professora titular na Universidade do Estado de Mato Grosso e no Programa de Pós-graduação em Educação da Universidade do Estado de Mato Grosso, Brasil. E-mail: maritzacmaldonado@gmail.com
} 
Bóra pescá pacú com caniço?

(Lívia, 06 anos)

\section{1 Às margens}

Ziguezaguear entre as infâncias e as crianças é o convite desse texto. No encontro com ideias, movimentos, linhas de intensidades, sensações e silêncios escrevemos em relação ao modo de pensar e de viver uma vida bonita, dando as costas aos aprisionamentos. A arte de viver infantis ribeirinhas. As infâncias que pululam com a vida ordinária. As crianças ribeirinhasamazônidas que produzem aprendimentos no toque às árvores e banhos de rio. Por meio de uma pesquisa realizada durante o Mestrado em Educação, vivenciamos e experienciamos a novidade da infância beiradeira. A infância que habita um outro lugar não requerido pelo projeto moderno. Jeito ziguezagueante entre as fissuras que a história contínua e linear nos acostumou.

Cartografamos a infância de crianças desordeiras que vivenciam a vida na beira de um rio em meio à floresta amazônica. Produzimos encontros, deixamos nos afetar pelas vozes e singularidades que expressam o quanto as crianças são enigmáticas aos olhos de quem procura utilidade a tudo e em todos. Às margens de um rio, encontramos crianças que criam experiências cotidianas e tombam o nosso pensamento adultocêntrico de captura e objetivação de suas subjetividades. Crianças que nos apresentaram a experiência infantil não preexistente, inventada. Nesse movimento, conhecemos os saberes e fazeres que as interpela dia a dia atinando-as ao modo de viver intensivo em meio à floresta.

A pesquisa se aproximou de vidas infantis que transversalizam entre às árvores, pássaros, rios e estórias. Saímos da História, (re)contada e reproduzida, para entrar na vida. A vida enquanto vontade de potência e de criação. Fomos ao encontro das vozes infantis inaudíveis, tivemos o ímpeto de ouvir o que as crianças ribeirinhas-amazônidas criam em seus cotidianos. Com uma escuta atenta encontramos as narrativas das suas experiências-infantis e trazemos algumas nesse texto, no sentido de potencializar estudos que versem em relação às crianças e às infâncias, mostrando que outros olhares são possíveis. Novos olhares que minem com as explicações sobre o que é a criança? Ou, o que é a infância?

\section{Cartografias: entre fios e meandros}

Cartografar o espaço-tempo vivido pelas crianças ribeirinhas-amazônidas foi um processo desterritorializante de nossos pensamentos e certezas. Abraçadas com o pensamento de Deleuze percorremos trilhas infantis na composição de linhas rizomáticas que nos levaram a caminhos nunca imaginados. Produzimos mapas em meio às crianças, mapas que nos conduziam 
por linhas de intensidades provocativas, suspeitas e deslizantes. Deslizamos com as crianças em busca de suas feituras infantis enquanto praticantes de um cotidiano singular e irrepetível. Ouvimos suas estórias. Reescrevemos suas narrativas e praticamos junto delas aquele cotidiano à beira do rio. Fomos ao encontro de compreendermos o que nos inquietava e se traduzia na seguinte questão: como as crianças reverberam e criam táticas de resistências diante de tantos discursos que se enunciam sobre elas?

Esse movimento na/da pesquisa nos proporcionou afetar e nos deixar sermos afetadas por acontecimentos vividos e experienciados naquele lugar. Por isso a cartografia nos auxiliou, pois, "todas as entradas são boas, desde que as saídas sejam múltiplas" (ROLNIK, 1989). Segundo Rolnik (1989, p. 03) o cartógrafo: “é um verdadeiro antropófago: vive de expropriar, se apropriar, devorar e desovar, transvalorado. Está sempre buscando elementos/alimentos para compor suas cartografias". Agir por meio da cartografia foi produzir rizomas que se espalharam e deformaram em linhas de aprendizagem entre o acontecimento da pesquisa; os rizomas possibilitaram a criação de percursos em diferentes direções e, por serem flexíveis, nos propiciaram operarmos por meio de fluxos que desequilibraram os aparatos metodológicos que estavam em vias de ser-aí, reproduzidos nas pesquisas em ciências humanas para se chegar a dados finais. Como nos apontam os filósofos Deleuze e Guattari (1996, p. 77-76),

[...] somos atravessados por linhas, meridianos, geodésicas, trópicos, fusos, que não seguem o mesmo ritmo e não têm a mesma natureza. [...] $\mathrm{E}$ constantemente as linhas se cruzam, se superpõem a uma linha costumeira, se seguem por um certo tempo. [...] É uma questão de cartografia. Elas nos compõem, assim como compõem nosso mapa. Elas se transformam e podem penetrar uma na outra. Rizoma.

Assim, em acordo com os autores Deleuze e Guattari, a cartografia propiciou produzir linhas de intensidades inventivas no movimento da pesquisa. Encontramos e desencontramos com informações, saberes e fazeres. Produzimos mapas rizomáticos. Criamos trilhas de acesso para a obtenção do conhecimento. Para Deleuze e Guattari (1995, p. 31; 32) “O rizoma é feito somente de linhas: linhas de segmentaridade, de estratificação, como dimensões, mas também linha de fuga ou de desterritorialização como dimensão máxima. [...] O rizoma procede por variação, expansão, conquista, captura, picada”. A cartografia rizomática se conduz por táticas de desterritorializações e de fuga, opondo-se ao decalque que se caracteriza pela fixação, rigidez e reprodução. A cartografia é movimento. E em meio ao movimento cotidiano da pesquisa produzimos mapas das vivências infantis ribeirinhas-amazônidas.

O mapa é aberto, é conectável em todas as suas dimensões, desmontável, reversível, suscetível de receber modificações constantemente. Ele pode ser rasgado, revertido, adaptar-se a montagens de qualquer natureza, ser preparado por um indivíduo, um grupo, uma formação social. Pode-se desenhá-lo numa parede, concebê-lo como obra de arte, construí-lo como uma ação política ou como uma meditação. Uma das características mais importantes 
do rizoma talvez seja a de ter sempre múltiplas entradas; [...] Um mapa tem múltiplas entradas contrariamente ao decalque que sempre volta ao 'mesmo'.

(DELEUZE; GUATTARI, 1995, p. 22).

Entendemos que para pesquisar com crianças é necessário utilizar de diversos meios para atrair sua atenção para, por conseguinte, adquirirem confiança e aproximação. Diante disso, os mapas rizomáticos, por oferecerem múltiplas entradas, exigiram que utilizássemos da criatividade ao produzir o percurso da investigação. Para tanto, brincamos, conversamos, navegamos de lancha escolar, voadeira (embarcação fluvial), pescamos, filmamos e anotamos. A cartografia nos proporcionou acompanhar os movimentos infantis ribeirinhos, oferecendonos uma maneira dialógica e atrativa no trato com as crianças, o que favoreceu conhecer as tessituras de saberes e fazeres infantis que se produzem à beira do rio e o que inventam junto às comunidades que ali habitam, como também a constituição da infância ribeirinha-amazônida que se caracteriza como força e resistência frente às políticas de captura da máquina capitalística.

\section{Hecceidades infantis: modos de individuações sem sujeito}

Na tessitura da pesquisa, na produção cartográfica e entre os fios e meandros encontramos as narrativas infantis ribeirinhas. Desejávamos ouvir das crianças suas operações astuciosas e clandestinas pouco observadas no mundo tomado pelas grandes narrativas. Narrar as práticas comuns do dia a dia foi abrir caminhos para as estórias ordinárias. As estórias ordinárias rompem com os discursos que são tomados como 'verdades' no mundo. Por isso fomos em busca da criança "ordinária", a criança que inventa o "cotidiano com mil maneiras de caça não autorizada" (CERTEAU, 1998, p. 38).

As crianças ribeirinhas-amazônidas se movimentam como rizomas e desterritorializamse dos discursos que enunciam sobre a infância e a criança, abrem conexões com outros campos, produzem bulbos, saltam por linhas de fuga, desconstroem nossas concepções de infância/ criança, como nos diz Maldonado (2017), dão bundacanastra ao mundo tomado pelo capitalismo de ordem e reprodução. Ao encontrarmos as narrações das experiências-infantis ribeirinhas, criativas e desordeiras, observamos o quanto são enigmáticas e compõem a novidade da vida, a vida enquanto afirmação e modos de individuações.

Nas narrativas encontramos as individuações (hecceidades), o que para Deleuze e Guattari (1997, p. 41), "não são simples arranjos, mas individuações concretas valendo por si mesmas e comandando a metamorfose das coisas e dos sujeitos". As hecceidades se movimentam no plano de composição das experiências cotidianas e produzem metamorfoses na criação de um novo início. "Uma hecceidade não tem nem começo nem fim, nem origem nem destinação; está sempre no meio. Não é feita de pontos, mas apenas de linhas. Ela é rizoma" (DELEUZE; GUATTARI, 1997, p.43). As hecceidades são rizomas que circulam entre 
os meios entrecruzando as potencialidades da vida num processo contínuo, sem começo ou fim, por isso não se constituem como Ser mas na conjunção E.

Não se acreditará que a hecceidade consista simplesmente num cenário ou num fundo que situaria os sujeitos, nem em apêndices que segurariam as coisas e as pessoas no chão. É todo o agenciamento em seu conjunto individuado que é uma hecceidade; é ele que se define por uma longitude e uma latitude, por velocidades e afectos, independentemente das formas e dos sujeitos que pertencem tão somente a outro plano. É o próprio lobo, ou o cavalo, ou a criança que param de ser sujeitos para se tornarem acontecimentos em agenciamentos que não se separam de uma hora, de uma estação, de uma atmosfera, de um ar, de uma vida (DELEUZE; GUATTARI, 1997, p. 43).

As crianças ribeirinhas-amazônidas produzem acontecimentos-experiências e agenciamentos com o meio que as interpela no dia a dia, ora fazem agenciamentos com o rio; ora com as árvores; ora com os animais. Estão em seu habitat afetando e deixando-se afetar pela linguagem que compõe suas singularidades. Como na narrativa abaixo:

Ana: Professora, você conhece um castanhal?

Pesquisadoras: Sim, já vi

Ana: Mas não é como o nosso castanhal. Professora, bóra lá conhecer?

Pesquisadoras: Vamos sim.

(ANA, 05 anos).

O castanhal que Ana nos convida para conhecer é singular, como nos ensinam Deleuze e Guattari ao falarem de hecceidade. Desse modo, o sentido atribuído à castanheira pelas crianças ribeirinhas-amazônidas é dotado de individuação que se distingue pelo referenciamento singular emanado de afetos ao falar do castanhal. Por isso, podemos deixar de lado a ideia de que há um único caminho que sustenta a compreensão de todas as coisas, como uma ideia perfeita, ou uma superestrutura. Não há caminho certo. Há, apenas, agenciamentos.

As crianças ribeirinhas-amazônidas definem suas individuações pelos agenciamentos com os conjuntos de elementos discursivos presentes nos ambientes que as atravessam, as movimentam, as tocam e lhes despertam afecções, sentidos e sensações singulares. Essas crianças mostram a necessidade de "transver o mundo" para encontrar novas maneiras de sentir e perceber a diferença de sentidos que existem quando nos dizem sobre suas afecções, assim como nos diz Barros (2010, p. 449), ao expressar alguns sentidos: "eu via a manhã pousada sobre as margens do rio". As afecções, as sensações e os sentidos gerados em seu ambiente fazem comunhão com tudo o que as permeiam, lhes despertando diferentes sentimentos, e nós, estando entre, tivemos o prazer de presenciar e senti-los.

E continuamos com as estórias: 
Pesquisadoras: Menino, você não tem medo de cobra?

Mário: Não professora, aqui tem muita cobra, a gente só tem que ter cuidado com elas. Eu já fui picado uma vez.

Pesquisadoras: Como aconteceu?

Mário: A cobra me picou no calcanhar. Um dia, eu tinha que passar pela ponte que tem na minha comunidade, mas dai resolvi passar por debaixo da ponte e uma cobra me picou. Na hora me deram um remédio chamado Específico. Esse remédio não deixa o veneno da cobra matar a gente. Daí, deu tempo de descer o rio de barco e chegar no postinho. Lá no postinho me deram soro e mandaram eu pro hospital de avião. Acho que porque estavam com medo de eu morrer. (MÁRIO, 05 anos).

Os acontecimentos-experiências infantis ribeirinhos tombam nossos pensamentos modernos pré-fixados. As crianças ribeirinhas-amazônidas são as descontinuidades de nossas certezas. "Não [são] o começo de um processo mais ou menos antecipável, mas uma origem absoluta, um verdadeiro início" (LARROSA, 2015a, p. 187). O início anunciado na vida infantil ribeirinha e em suas estórias desconstroem a presunção de convertê-las em um de nós e as incorporar em nosso mundo, pois suas vivências interrompem toda uma cronologia de ordem e repetição que temos em nossas casas e em nossas instituições de governamentalidade. Em acordo com o pensamento de Nietzsche, a criança "[...] é um novo começo, um jogo, uma roda a girar por si mesma, um primeiro movimento, um sagrado dizer-sim" (NIETZSCHE, Assim falou Zaratustra, Das três metamorfoses). Dizer-sim para um novo começo é reconhecer a alteridade que as crianças e as infâncias trazem consigo.

A alteridade das infâncias é o Outro de nosso saber que escapa e desvia dos tantos discursos que se enunciam sobre elas. "A alteridade da infância é algo muito mais radical: nada mais, nada menos que sua absoluta heterogeneidade em relação a nós e ao nosso mundo, sua absoluta diferença" (LARROSA, 2015a, p. 185). Por assim dizer, as infâncias e as crianças criam liames e tramas que inquietam nossas vontades de saber e colocam em suspensão nossa arrogância da vontade de poder em reproduzir mecanismos de controle de suas singularidades, pois nos planos de composição de suas hecceidades compostas por nomes próprios (sem sujeito), deslizam na conjugação de verbos no infinitivo e de artigos e pronomes indefinidos.

Os nomes próprios (sem sujeito) indicam suas singularidades particulares. Nas palavras de Deleuze e Guattari (1997, p. 44), “O nome próprio não é o sujeito de um tempo, mas o agente de um infinitivo". O nome próprio é a singularidade que se movimenta em velocidades que o compõe e os afectos que o preenche, expressos nos acontecimentos que encontramos no devircriança. O devir-criança não imita algo ou alguém. O devir,

[...] é, a partir das formas que se tem, do sujeito que se é, dos órgãos que se possui ou das funções que se preenche, extrair partículas, entre as quais instauramos relações de movimento e repouso, de velocidade e lentidão, as mais próximas daquilo que estamos em vias de nos tornarmos, e através das quais nos tornamos. (DELEUZE; GUATTARI, 1997, p. 55) 
O devir-criança é o processo criativo de algo novo que indica outras possibilidades, outras experiências e linhas de fuga. "Devir é se encontrar no acontecimento, no movimento, na multiplicidade, com algo sem passado, presente ou futuro; algo sem temporalidade cronológica, mas com geografia, com intensidade e direção próprias. Um devir é algo sempre contemporâneo" (KOHAN, 2008, p. 50). As crianças ribeirinhas são preenchidas por acontecimentos-experiências que manifestam o devir-criança, que as conduz a procederem por intersecções, cruzamentos de linhas, ponto de encontros no meio; não são sujeitos, mas agenciamentos coletivos de enunciação. “Acontecimento é o que não pode ser previsto, nem compreendido, nem especificado, nem controlado; é o que escapa a qualquer tentativa de apreensão" (LARROSA, 2001, p. 285). As crianças desdobram o tempo medido em narrações de suas vivências infantis ribeirinhas que constituem suas subjetividades. Por meio de suas vivências ecoam suas multiplicidades. Diante disso, Monteiro (2012, p. 20) sinaliza "é por meio das vivências que nos tornamos o que somos". As vivências infantis são suas experiências intensivas, no plano de composição é a própria individuação.

Em Ecce homo (Porque escrevo livros tão bons, §1) Nietzsche registra: "para aquilo a que não se tem acesso por vivência, não se tem ouvido". Nesse caso, simplesmente nada é ouvido se não nos dispusermos a sentir as infâncias e as crianças com mais sutileza e admiração por seus aprendimentos. Trazer para este texto as narrativas infantis ribeirinhas é algo de significativa consistência no sentido de desconstruir conceitos e teorias que se valem de 'um lugar para a infância'. Ouvir as crianças foi um grande aprendizado. Quando narram suas vivências infantis ribeirinhas ressoam suas experiências 'sentidas na pele' que não carecem de explicações racionais, pois a experiência vivida é a presença imediata de alguém que vivenciou efetivamente um acontecimento e produziu sensações, afectos e perceptos (DELEUZE; GUATTARI, 1997).

A vivência está estritamente ligada à vida. A vida enquanto afirmação e vontade de potência.

\begin{abstract}
E sabeis sequer o que é para mim "o mundo"? Devo mostrá- -lo a vós em meu espelho? Este mundo: uma monstruosidade de força, sem início, sem fim, uma firme, brônzea grandeza de força, que não se torna maior, nem menor, que não se consome, mas apenas se transmuda, [...] - Esse mundo é a vontade de potência - e nada além disso! E também vós próprios sois essa vontade de potência - e nada além disso (NIETZSCHE, Fragmento Póstumo, 38 [12] junho - julho de 1885).
\end{abstract}

A vida é vontade de potência. Para o filósofo Nietzsche, trata-se de um complexo jogo de forças que estão permanentemente em conflitos. Nesse jogo de forças a criança não interpreta relações e situações, age por devires e cria, desestabiliza a ordem, é desordeira da linguagem dominante. Diante disso, afirma sua absoluta diferença em relação ao que nossos saberes, nossas práticas e nossas instituições já capturaram (LARROSA, 2015a, p. 184). Como 
observamos na estória seguinte:

Bill: Professora, bóra conhecer a beira?

E fomos conhecer a beira do rio. Chegando lá,

Bill: Professora essa é a beira do rio, é aqui que a gente toma banho todos os dias, brincamos e a mamãe lava roupa. A gente gosta muito depois da aula vir aqui brincar no rio. O nome desse rio é Guariba, dizem que tem esse nome, porque nessas matas têm muito macaco Guariba. Não sei se é verdade, mas já vi um bocado deles. O macaco Guariba tem o pelo vermeio e sempre foge quando vê a gente. Aqui na beira tem muito piun, você conhece o mosquito piun? Esse mosquito só aparece na época que o rio tá cheio, igual agora, e fica incomodando a gente. Na época da seca é mais bom, o mosquito some, e a gente pode brincar sossegado na beira do rio.

(Bill, 05 anos).

As crianças ribeirinhas-amazônidas nos mostram uma nova percepção do mundo; a essa outra maneira de encontrar com o mundo, os autores Guattari e Rolnik dão o nome de singularização, ou seja,

[...] uma maneira de recusar todos esses modos de encodificação preestabelecidos, todos esses modos de manipulação e de telecomando, recusá-los para construir, de certa forma, modos de sensibilidade, modos de relação com o outro, modos de produção, modos de criatividade que produzam uma subjetividade singular. Uma singularização existencial que coincida com um desejo, com gosto de viver; com uma vontade de construir o mundo no qual nos encontramos, com a instauração de dispositivos para mudar os tipos de sociedade, os tipos de valores que não são os nossos. (GUATTARI; ROLNIK, 1996, p. 17).

Desse modo, deslizando entre novos caminhos, as infâncias das crianças ribeirinhasamazônidas demonstram o quanto é impossível a universalização das infâncias. A racionalidade dominante não participa do jogo de forças que acontecem no espaço vivido ribeirinho. As vivências infantis ribeirinhas pertencem à desordem da experiência, como cita Larrosa (2015b, p. 40), "a experiência sempre é de alguém, subjetiva, é sempre daqui e de agora, contextual, finita, provisória, sensível, mortal, de carne e osso, como a própria vida”. Por isso, a linguagem dominante que trata as crianças e/ou as infâncias como algo a ser interpretado, procurando fins e meios para desmistificá-los, são ineficazes.

As hecceidades infantis ribeirinhas, seus modos de individuações, não são sujeitados a uma linguagem unívoca. Suas relações no espaço e tempo não são resultado de uma causalidade, pois na composição do cotidiano são multiplicidades advindas de muitas direções. "O plano de consistência só contém hecceidades segundo linhas que se entrecruzam" (DELEUZE; GUATTARI, 1997, p. 43). As linhas são os vetores de forças que impulsionam a se efetivar enquanto potência. A vontade de potência é aquilo que se cria, transvalora o logos; não reproduz, 
compõe; não fabrica, inventa. As linhas de composição das subjetividades infantis ribeirinhas compõem e inventam desvios. Os desvios, "[são] a marca imperceptível da autenticidade que os distingue de todos os objetos em série fabricados segundo um padrão" (BENJAMIN, 1993, p. 264).

Ziguezagueando com as crianças e as infâncias que vivem no plural, entrando junto com elas nos desvios do mundo, encontramos vidas não fabricadas pelo discurso moderno. E, em meio a todas essas potencialidades das infâncias ribeirinhas-amazônidas, pensamos o quanto estas são deslocadas de um discurso hegemônico e nos afastam de tantas estratégias institucionalizadas que insistem em fabricar modelos ontológicos e políticos sobre a infância. As crianças são afirmações e rupturas, como lembra Manoel de Barros, as crianças "não querem mais ser vistas por pessoas razoáveis: elas desejam ser olhadas de azul - que nem uma criança que você olha de ave" (BARROS, 2010, p. 302).

\section{Por fim, enfim, sem fim}

Infantilices e meninices encontramos na pesquisa com a infância das crianças ribeirinhasamazônidas vivenciada em uma instituição de Educação Infantil. Nesse encontro observamos que as crianças e as infâncias não podem ser reduzidas a um conjunto de métodos, pressupostos, teorias e/ou até os objetivos da escola que procuram categorizá-las e defini-las. Na tessitura dos cotidianos, as crianças e as infâncias, assumem seus devires como forças de criação da novidade. A novidade é a origem absoluta de que outros modos de ver, sentir e pensar são possíveis em relação à alteridade das crianças e suas infâncias. É possível afirmar que o iluminismo - a razão - apostou no sucesso da humanidade baseado em estudos e teorias que reproduzem técnicas e métodos racionalizados, fundados em discurso universal aplicável às nações, às culturas, à educação de massa na busca do progresso em vias de projetar nas crianças os futuros cidadãos, bons e suscetíveis ao mercado de trabalho. Engano.

Embora estejamos capturados pela malha dos discursos hegemônicos que silenciam as multiplicidades, as crianças e as infâncias estão ali, movimentando, afetando e se deixando afetar em meio aos cotidianos de afirmação de suas vidas. Estão movimentando os espaços e tempos de subjetivação, as culturas, as escolas. Foram esses movimentos que nos propusemos pesquisar, cartografando rastros de crianças e infâncias que vivem nos plurais, forças que resistem e racham com os estratos molares de nossas redes de objetivação. As crianças e as infâncias não estão adversárias do mundo capitalístico, pelo contrário, estão como praticantes operacionais de mudanças (OLIVEIRA, 2007, p. 67).

Portanto, não há o caminho certo. Vivenciamos no dia a dia por caminhos intensivos e criativos que afirmam o quanto as crianças e as infâncias são potências. Nós, professoraspesquisadoras, defendemos a necessidade de olhar com mais sutileza as experiências de vidas enquanto acontecimentos que criam erupções, escapes e variações em seu espaço e tempo de 
subjetivação como a escola. Vivenciando entre os cotidianos escolares, quem sabe possamos, junto às crianças e às infâncias, fazer traçados que rachem com os extratos de processos de ensino e aprendizagem engessados e excludentes. Por fim, quiçá possamos experimentar a diferença, desordenar as normas para pensar a instituição de Educação Infantil como território de multiplicidades, somas, desejos, desterritorializações, cultivo de alegrias, afectos e reterritorializações. Enfim, romper com 'o lugar da criança' e da 'infância', pois elas/eles estão nos lugares mais ínfimos. Como nos presenteia o poeta Barros (2010, p. 350) em seu linguajar do brincar: "Fazer cavalo verde, por exemplo". Sem fim.

\section{Notas}

${ }^{1}$ Este artigo foi extraído do relatório final da pesquisa de Mestrado em Educação.

${ }^{2}$ Termo adotado na pesquisa para nominar crianças ribeirinhas que vivem na floresta amazônica. ${ }^{3}$ Os nomes atribuídos às crianças que participaram da pesquisa são fictícios em atendimento às normas do Comitê de Ética.

${ }^{4} \mathrm{O}$ termo Outro, neste texto, refere-se à alteridade das crianças e às infâncias que escapam às tentativas de objetivação dos discursos totalizantes.

\section{Referências}

BARROS, M. Poesia completa. São Paulo: Leya, 2010.

BEnJAMIn, W. O Conceito de Crítica de Arte no Romantismo Alemão. São Paulo: Iluminuras, 1993.

CERTEAU, M. A invenção do cotidiano: 1. Artes de fazer. Petrópolis - RJ: Editora vozes, 1998.

DELEUZE, G.; GUATTARI, F. Mil platôs: capitalismo e esquizofrenia. São Paulo: Ed. 34, v.1, 1995.

DELEUZE, G.; GUATTARI, F.. Mil platôs: capitalismo e esquizofrenia. São Paulo: Ed 34, Vol.3, 1996.

DELEUZE, G.; GUATTARI, F.. Mil platôs: capitalismo e esquizofrenia. São Paulo: Ed 34, Vol.4, 1997.

GUATTARI, F.;ROLNIK, S. Micropolítica: Cartografias do desejo. 4 ed. Petrópolis: Vozes, 
1996.

KOHAN, W. O. Infância e Filosofia. In: SARMENTO, Manuel; GOUVEIA, Maria Cristina Soares de. (Orgs). Estudos da Infância Educação e práticas sociais. Petrópolis: Vozes, 2008 .

LARROSA, J. Dar a palavra. Notas para uma dialógica da transmissão. In: LARROSA, J.; SKLIAR, C. (Orgs.). Habitantes de Babel: políticas e poéticas da diferença. Belo Horizonte: Autêntica, 2001.

LARROSA, J. Pedagogia Profana: danças, piruetas e mascaradas. Belo Horizonte: Autêntica editora, 2015a.

LARROSA, J.. Tremores: escritos sobre experiência. Belo Horizonte: Autêntica, 2015b

MALDONADO, M. M. C. Espaço Pantaneiro: cenário de subjetivação da criança ribeirinha. Curitiba, CRV, 2017.

MONTEIRO, S. B. Quando a pedagogia forma professores: uma investigação otobiográfica. Cuiabá: EdUFMT, 2013.

NIETZSCHE, F. Assim Falou Zaratustra. Trad. Paulo César de Souza. Companhia das Letras: São Paulo, 2011.

NIETZSCHE, F. Ecce Homo. Trad. Paulo César de Souza. Companhia das Letras: São Paulo, 1995.

NIETZSCHE, F. Fragmentos Póstumos. 1884-1885. Vol. V. Trad. Marco Antônio Casanova. Rio de Janeiro: Forense Universitária, 2015.

ROLNIK, S. Cartografia Sentimental: transformações contemporâneas do desejo. São Paulo: Estação Liberdade, 1989.

OLIVEIRA, I.B. Aprendendo nos/dos/com os cotidianos a ver/ ler/ouvir/sentir o mundo. In: Educ. Soc., Campinas, vol. 28, n. 98, p. 47-72, jan./abr. 2007. Disponível em: http://http:// www.scielo.br/pdf/es/v28n98/a04v2898.pdf . Acesso: 28 mar. 2019.

Recebido:01/08/2019 Aprovado: 24/11/2019 